\title{
XB130 promotes bronchioalveolar stem cell and Club cell proliferation in airway epithelial repair and regeneration
}

\author{
Hiroaki Toba $^{1}$, Yingchun Wang ${ }^{1}$, Xiaohui Bai ${ }^{1}$, Ricardo Zamel ${ }^{1}$, Hae-Ra Cho ${ }^{1}$, \\ Hongmei Liu ${ }^{1}$, Alonso Lira ${ }^{1}$, Shaf Keshavjee ${ }^{1,2,3}$, Mingyao Liu ${ }^{1,2,3}$ \\ ${ }^{1}$ Latner Thoracic Surgery Research Laboratories, Toronto General Research Institute, Universal Health Network, Toronto, \\ ON, Canada \\ ${ }^{2}$ Department of Surgery, Faculty of Medicine, University of Toronto, Toronto, ON, Canada \\ ${ }^{3}$ Institute of Medical Science, Faculty of Medicine, University of Toronto, Toronto, ON, Canada \\ Correspondence to: \\ Mingyao Liu, e-mail: mingyao.liu@utoronto.ca \\ Keywords: naphthalene, small airway injury and repair, bronchioalveolar duct junction, PI3K/AKt signaling, transgenic mice \\ Received: July 09, $2015 \quad$ Accepted: August 21, $2015 \quad$ Published: September 03, 2015
}

\section{ABSTRACT}

Proliferation of bronchioalveolar stem cells (BASCs) is essential for epithelial repair. XB130 is a novel adaptor protein involved in the regulation of epithelial cell survival, proliferation and migration through the PI3K/Akt pathway. To determine the role of XB130 in airway epithelial injury repair and regeneration, a naphthaleneinduced airway epithelial injury model was used with XB130 knockout (KO) mice and their wild type (WT) littermates. In XB130 KO mice, at days 7 and 14, small airway epithelium repair was significantly delayed with fewer number of Club cells (previously called Clara cells). CCSP (Club cell secreted protein) mRNA expression was also significantly lower in $\mathrm{KO}$ mice at day 7 . At day 5 , there were significantly fewer proliferative epithelial cells in the KO group, and the number of BASCs significantly increased in WT mice but not in KO mice. At day 7, phosphorylation of Akt, GSK-3 $\beta$, and the p85 $\alpha$ subunit of PI3K was observed in airway epithelial cells in WT mice, but to a much lesser extent in KO mice. Microarray data also suggest that PI3K/Akt-related signals were regulated differently in KO and WT mice. An inhibitory mechanism for cell proliferation and cell cycle progression was suggested in KO mice. XB130 is involved in bronchioalveolar stem cell and Club cell proliferation, likely through the PI3K/Akt/GSK-3 $\beta$ pathway.

\section{INTRODUCTION}

The lung epithelium provides an important defense mechanism against various infectious and noxious substances in the air. Repair and regeneration of the epithelium after injury is essential for normal function. Improper tissue repair and remodeling leads to lung diseases, including chronic obstructive pulmonary disease, asthma and pulmonary fibrosis [1].

In the bronchioles, epithelial cells consist of both ciliated cells and non-ciliated Club cells (previously called Clara cells). Club cells are much more abundant, accounting for $70-90 \%$ of epithelial cells in mice [2]. Naphthalene is an environmental pollutant that specifically ablates Club cells [3], and is commonly used as a model to study small airway injury and repair $[4,5]$. Following naphthalene injury, a small subset of surviving Club cells, variant Club cells, is found at the bronchioalveolar duct junctions (BADJs) [6]. They proliferate and differentiate into Club cells, which leads to the renewal of the small airway epithelium [7]. These cells have been proposed as bronchioalveolar stem cells (BASCs), located at the BADJs [8]. Under certain circumstances, BASCs also contribute to the regeneration of alveolar cells [8], thus playing important roles in the repair and regeneration of terminal bronchioles and alveoli.

Several intracellular signal transduction pathways have been suggested to regulate the proliferation and differentiation of BASCs. The PI3K pathway has been proposed as a critical regulator of BASC expansion [9]. Using a transgenic approach, Tiozzo and co-workers selectively deleted Pten, a negative regulator of the 
PI3K pathway, in lung epithelial cells. This deletion increased BASCs at the BADJs, and conferred a selective advantage to naphthalene injury in these cells [10]. Further exploration of the role of molecules in the PI3K pathway may enhance our knowledge of how bronchial epithelial repair and regeneration is regulated.

XB130 (also called AFAP1L2, for actin filament associated protein 1 like 2) is a novel adaptor protein for intracellular signal transduction [11]. It regulates cell cycle progression, prevents cell death, and promotes cell migration through its binding with $\mathrm{p} 85 \alpha$, the regulatory subunit of PI3K, and subsequently activates the PI3K/Akt signaling pathway [12-14]. XB130 protein is found in various epithelial cells in the stomach [15] esophagus [16] and thyroid [17] and its potential as a signal transduction protein has been investigated in vitro [18, 19]. Using XB130 knockout (KO) mice, it has been shown that XB130 deficiency affects tracheal epithelial differentiation during airway repair [20]. Nicotine-derived nitrosamine ketone (NNK) is the most potent carcinogen among cigarette smoking components. Recently, it has been shown that XB130 mediates NNK-induced migration of human bronchial airway epithelial cells [21]. However, little is known about the function of XB130 in bronchial airways in vivo. We hypothesized that the absence of XB130 leads to greater susceptibility to severe injury, and delays epithelial cell repair through the PI3K/Akt pathway. This hypothesis was tested with the naphthalene-induced airway epithelial injury model using XB130 knock out (KO) mice.

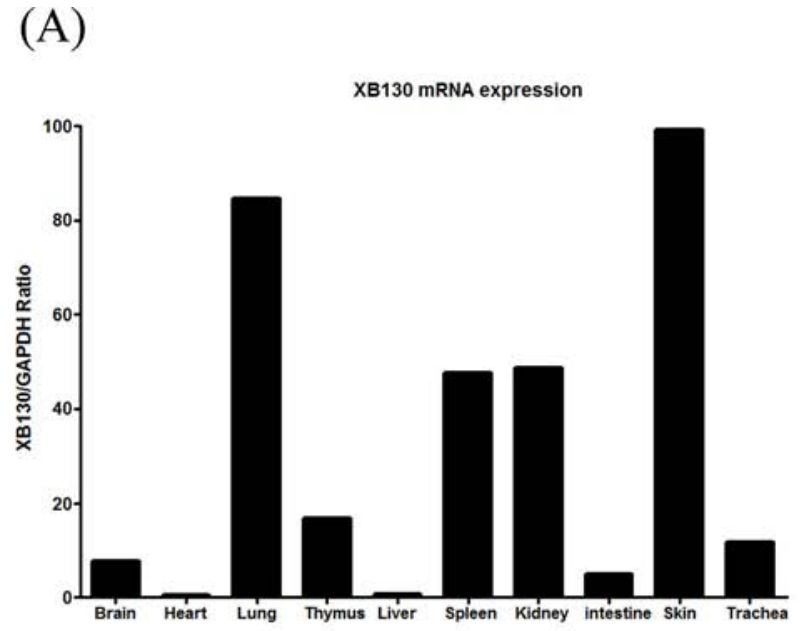

\section{RESULTS}

\section{XB130 is highly expressed in the bronchial epithelium of normal mouse lung}

We examined the $X B 130$ mRNA expression in various mouse organ tissues of WT mice. The XB130 mRNA expression in mouse lung was relatively higher compared to other organs (Figure 1A). XB130 was strongly expressed in the cytoplasm of Club cells (Figure 1B), and as expected, no expression of XB130 was found in XB130 KO mice (data not shown). XB130 was also found in both type I and type II alveolar epithelial cells, but at a much lower level than in the airway epithelial cells (data not shown).

\section{XB130 deficiency leads to delay of airway epithelial repair}

Body weight loss is known to be a good marker of the severity of naphthalene-induced injury [22]. There was no significant difference in weight loss between WT and $\mathrm{KO}$ mice (Figure E1 in the online data supplement).

Under the control condition (day 2 after corn oil without naphthalene), the morphology of lung tissue is indistinguishable between the $\mathrm{KO}$ and $\mathrm{WT}$ groups (Figure 2A), suggesting that XB130 ablation has no effect on lung development. At day 2 after naphthalene treatment, many dead cells were detached from the basement membrane and sloughed into the airway lumen,
(B)

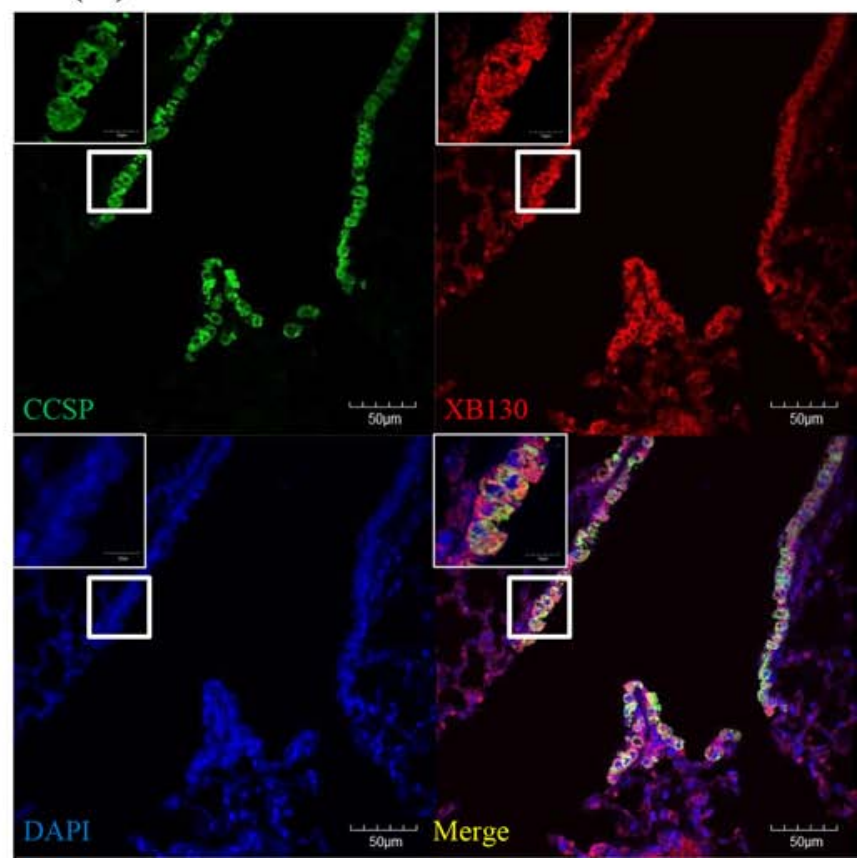

Figure 1: Expression of XB130 in murine small airway epithelial cells. A. The $X B 130 \mathrm{mRNA}$ level of normal mouse lung was relatively high compared to those of other organs studied, as determined by RT-PCR. B. Immunofluorescence studies show XB130 expression (XB130+, red) in Club cells (CCSP+, green) in the small airway epithelium of normal mouse lung. 
and the surface of the airway epithelium was covered by a thin layer of survival cells, in both WT and XB130 KO mice (Figure 2A). The bronchial airway epithelium gradually recovered after the injury at days 7 and 14; at day 14 , the morphology of bronchial airway epithelium in the WT mice appears similar to that of the control (Figure 2A). The cell death scores did not show significant differences between the two groups (Figure 2B). However, at days 7 and 14, the damaged areas of airway epithelium were significantly larger in KO mice (Figure 2A and 2C), suggesting a delay of bronchial airway epithelial repair.

\section{XB130 deficiency leads to reduced bronchial epithelial cell proliferation}

At day 2 after naphthalene treatment, most of the detached cells were apoptotic (data not shown). To assess the extent of cell death in airway lumen, we counted attached TUNEL+ cells in the airway wall at the BADJs (Figure 3A). There was no significant difference between the two groups (Figure 3B). At day 5, the number of
Ki-67+ cells, a marker for cell proliferation (Figure 3C), was significantly lower in $\mathrm{KO}$ mice (Figure 3D).

At days 7 and 14 after naphthalene treatment, the total number of airway epithelial cells quantified from H\&E staining at the BADJ were significantly less in the KO mice (Figure 4B). The number of CCSP+ cells (a marker for Club cells) [23, 24] was also significantly lower in the $\mathrm{KO}$ mice (Figure 4A, 4C). Furthermore, the CCSP mRNA expression was significantly lower in KO mice at day 7 (Figure 4D). These results suggest that XB130 may play an important role in airway epithelial cell regeneration at the BADJs after injury, especially by affecting Club cell proliferation.

\section{XB130 deficiency did not affect ciliated cells after injury}

In general, after Club cell ablation, ciliated cells are well known to cover the denuded basement membrane of the injured airway epithelium through cell spreading and migration $[5,25]$. To determine the role of XB130 on the
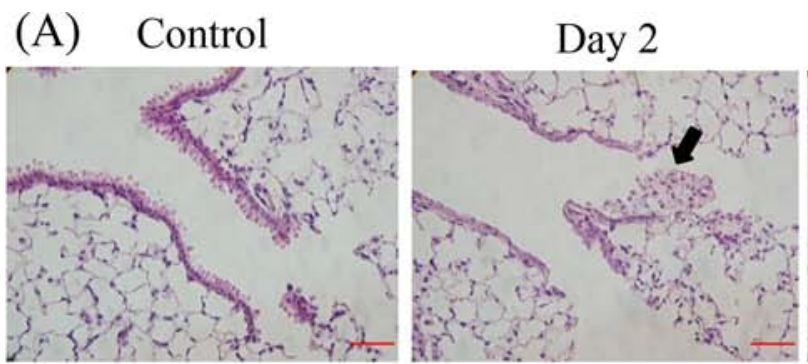

Day 7
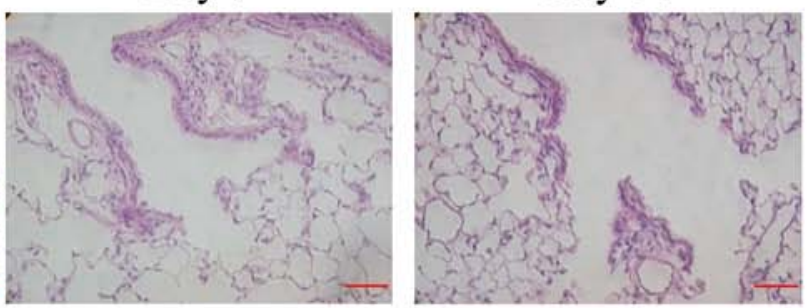
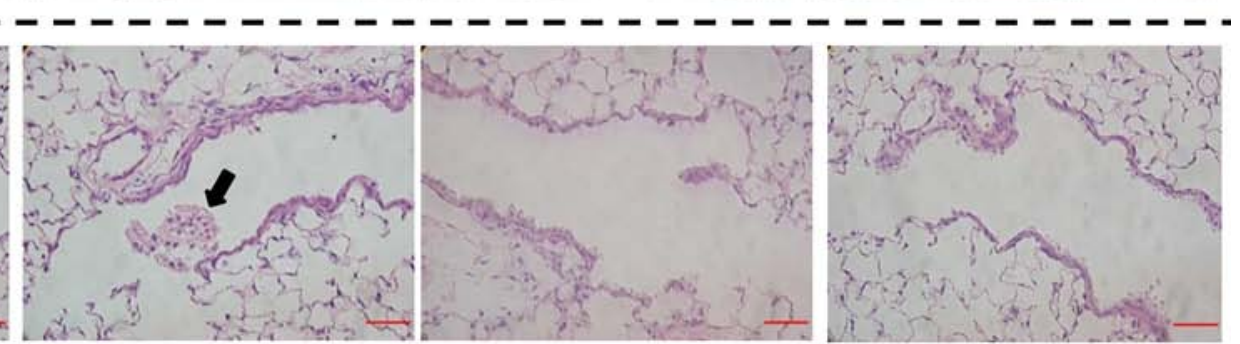

(B)

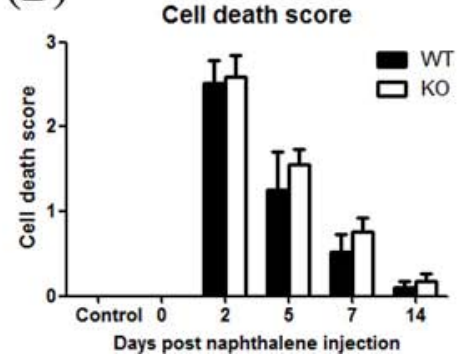

(C)

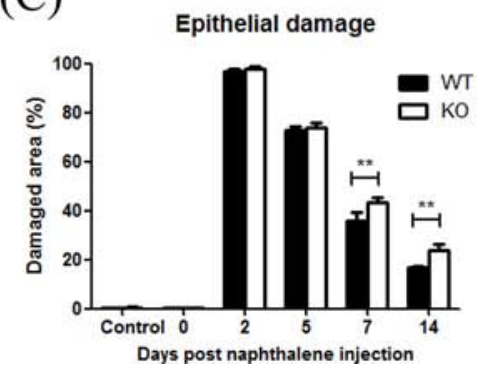

Figure 2: XB130 deficiency delayed the repair process after naphthalene-induced small airway epithelial damage. A. Naphthalene-induced small airway injury and repair. Representative histological changes of lung tissues at different stages of injury and repair from wild type (WT) and XB130 knockout (KO) mice. At day 2 after naphthalene treatment, many dead cells (arrow) were observed in the airway lumen in both groups. Scale Bars $=50 \mu \mathrm{m}$. B. The cell death scores did not show significant difference between two groups. C. At day 7 and 14, damaged area of airway epithelium was significantly larger in KO mice $(* * p<0.01)$. 
(A) Day 2

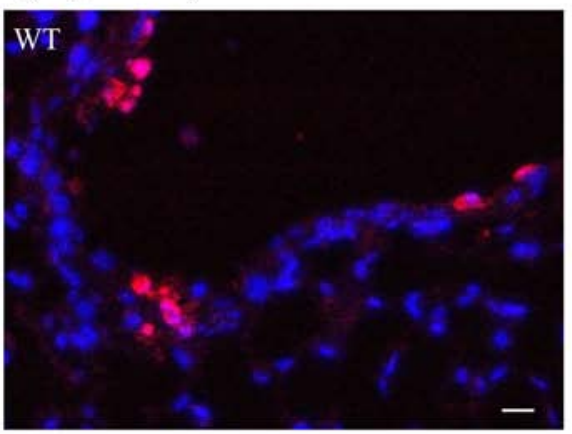

(C) Day 5

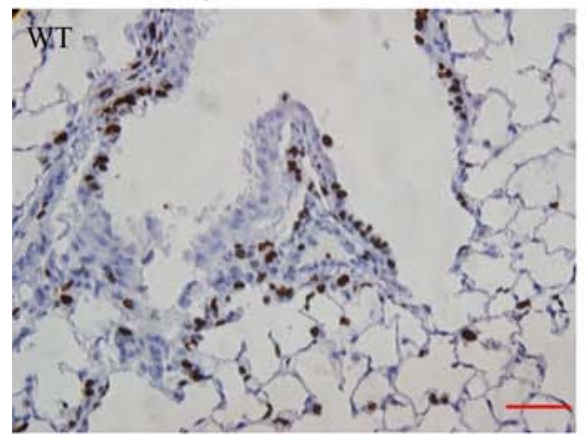

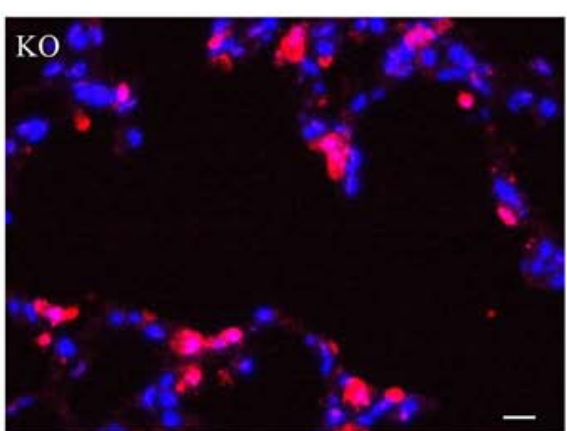

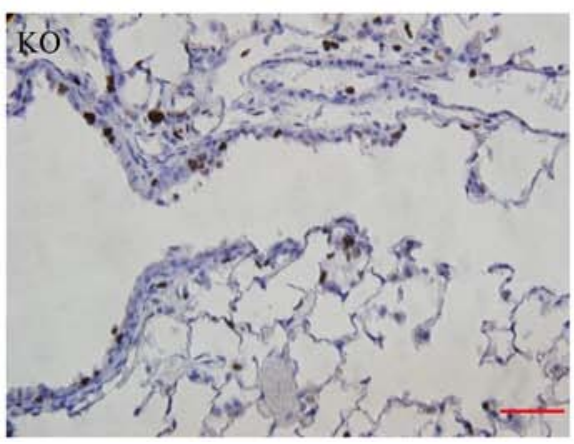

(B)

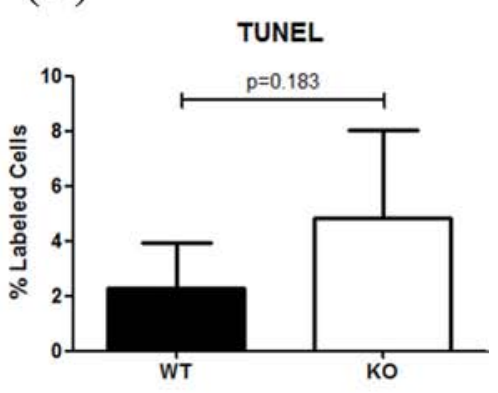

(D)

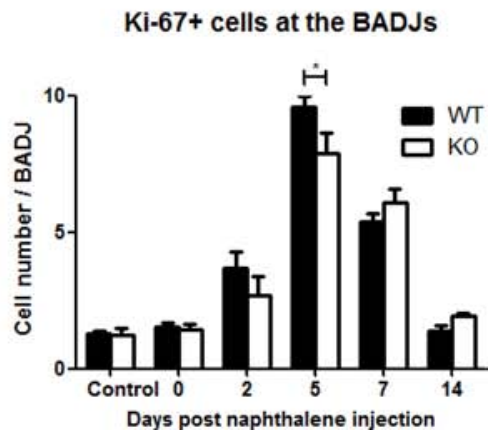

Figure 3: XB130 deficiency reduced cell proliferation during small airway epithelial repair. A, B. At day 2 after naphthalene treatment, apoptotic cells (red) were observed in both groups without significant difference. Scale Bars $=20 \mu \mathrm{m}$. C. At day 5, the number of proliferative (Ki-67+, brown) epithelial cells was less in KO mice. Scale Bars $=50 \mu \mathrm{m}$. D. Ki67+ cells were quantified as an index for cell proliferation at different time points. At day 5, the number of Ki67+ cells in KO mice was significantly less than that in WT mice $(* p<0.05)$.

behavior of both Club cells and ciliated cells during airway injury and repair, CCSP and $\beta$-tubulin IV (ciliated cell marker) $[26,27]$ double staining was performed (Figure 5). Under the control condition, the small airway was primarily covered with CCSP+ cells (Club cells, green). Two days after naphthalene treatment, the BADJ area was mainly covered by $\beta$-tubulin IV + cells (ciliated cells, red). At days 7 and 14, the number of CCSP+ cells increased at the BADJs in the WT mice and to a lesser extent in the $\mathrm{KO}$ mice (Figure 5A). At days 2 and 5, the number of $\beta$-tubulin IV+ cells increased at the BADJs and then gradually decreased in both groups (Figure 5B). The mRNA expression of $\beta$-tubulin IV and Foxj1 (another ciliated cell marker) [26, 27] was also not significantly different between the two groups (Figure 5C and 5D). On the other hand, the ratio of CCSP+ cells to $\beta$-tubulin IV+cells was significantly lower in $\mathrm{KO}$ mice at days 7 and 14 (Figure 5E).

In WT mice, the XB130 mRNA level was reduced in the lung tissue after naphthalene administration, and gradually recovered over time (Figure 6A). XB130 was co-stained with CCSP (for Club cells; Figure 6B Top), or with $\beta$-tubulin IV (for ciliated cells; Figure 6B Bottom). At day 2, when the small airway was mainly covered with ciliated cells, no XB130 expression was noted, whereas at day 14 , the recovery of Club cells was associated with XB130 expression (Figure 6B). These results suggest that
XB130 deficiency mainly affects the function of Club cells, not ciliated cells.

\section{XB130 deficiency slows down proliferation of bronchioalveolar stem cells}

We further tested whether XB130 deficiency also affects the local stem cells (variant Club cells, or BASCs). The BASCs were determined with co-IF staining for CCSP and Surfactant protein C (Sftpc) double positive cells at the BADJs [8, 28, 29]. Among CCSP+ cells, a few of them were $\mathrm{CCSP}+/ \mathrm{Sftpc}+$ cells (Figure 7A, white arrows). At day 5, the number of BASCs significantly increased compared to both days 0 and 14 and the control group in WT mice (Figure 7B). In KO mice, the number of BASCs also increased at days 5 and 7 but was not significantly different from other time points. Thus, XB130 deficiency reduced the proliferation of BASCs at the BADJs.

\section{XB130 deficiency reduced phosphorylation of proteins on PI3K/AKT pathway during airway epithelial repair}

Volckaert et al. showed that crosstalk between epithelial cells and parabronchial smooth muscle cells PSMCs contributed to airway epithelial repair 
(A)

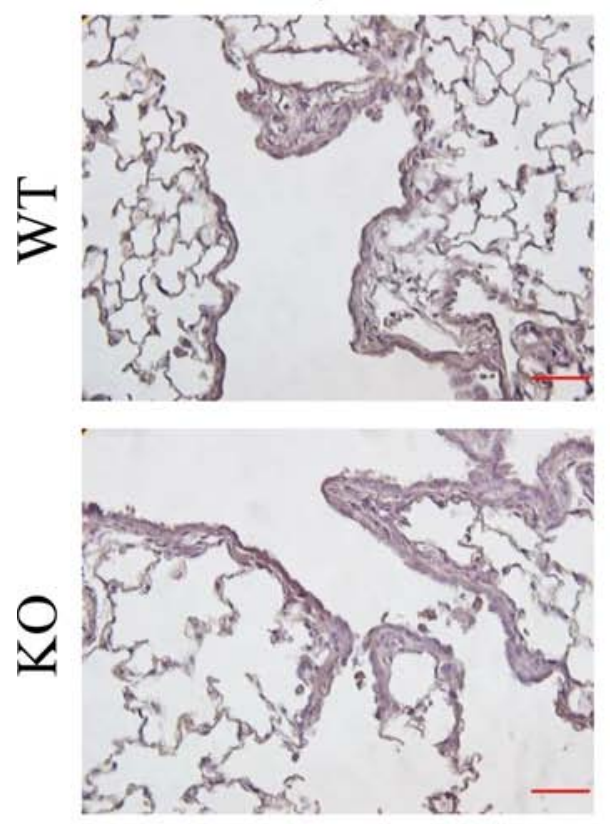

(B)

Number of cells at the BADJs

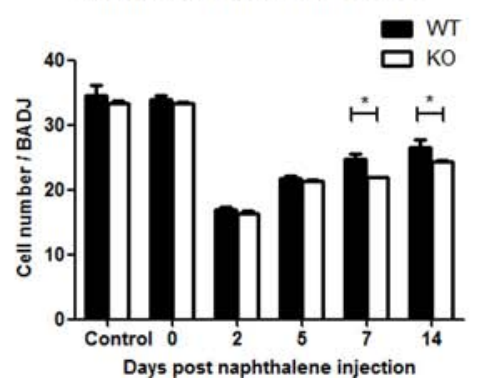

Day 7
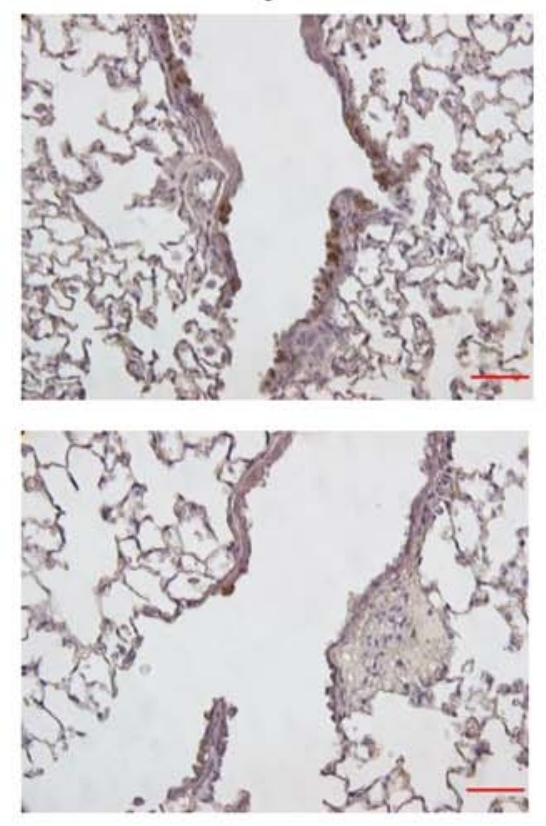

(C)

CCSP+ cells at the BADJs

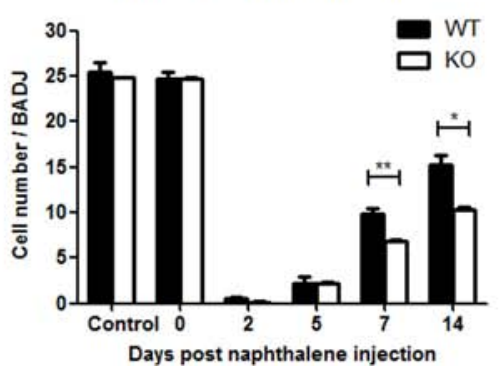

Day 14
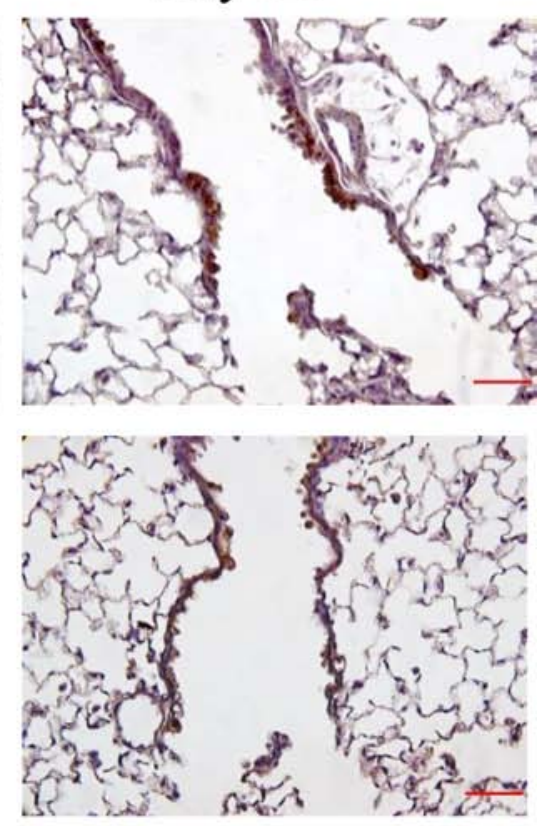

(D)

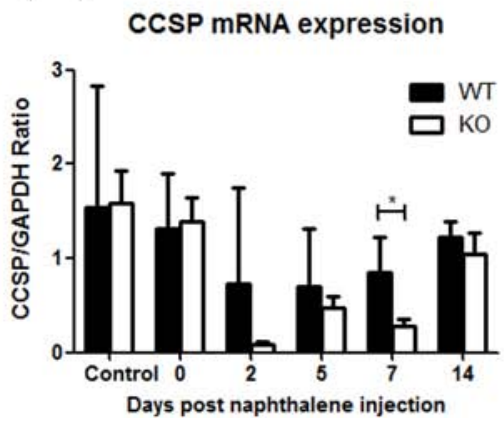

Figure 4: XB130 deficiency reduced Club cell proliferation during small airway epithelial repair. A. The number of Club cells was determined by immunohistochemistry staining. Less staining at day 7 and 14 was noted in KO mice. Scale Bars $=50 \mu \mathrm{m}$. At day 7 and 14 after naphthalene treatment, the number of total epithelial cells B. and Club cells (CCSP+) C. was significantly less at the bronchioalveolar duct junctions (BADJ) in KO mice. D. The CCSP mRNA expression was also significantly lower in KO mice at day 7. $(* p<0.05)$.

after naphthalene-induced injury through epithelial mesenchymal transition (EMT) [30]. After naphthalene challenge, surviving ciliated cells may stimulate PSMCs through Wnt7b, to induce the release of FGF10, which then stimulates variant Club cells (as local stem cells), initiating the epithelial repair process through a transient EMT (Figure 8A). To determine whether XB130 is involved in these processes, we examined the mRNA expression of EMT-related genes (Wnt7b, Fgf10, $\beta$-catenin and Snail1) with quantitative RT-PCR. There were no significant differences between WT and $\mathrm{KO}$ mice during the experimental period (Figure 8B-8E).

We have previously shown a specific binding interaction between XB130 and the p85 $\alpha$ subunit of PI3K [12], which affected cell proliferation and survival via Akt and multiple down-stream signals, including GSK-3 $\beta$ [13].
At day 7 after naphthalene treatment, phosphorylation of p $85 \alpha$, Akt and GSK-3 $\beta$ were observed in the small airways of WT mice, but was significantly less in KO mice (Figure 9A-9C).

\section{XB130 deficiency affected naphthalene-induced gene expression during lung repair}

To further determine the potential mechanisms by which XB130 deficiency affects airway repair, we performed microarray studies with RNA extracted from lung tissue 7 days after naphthalene challenge and from normal, untreated mice as controls. Seven days was chosen because multiple differences (e.g., epithelial damage, CCSP + cell number, CCSP gene expression, and phosphorylation of proteins in PI3K/Akt pathways) 
(A) Control
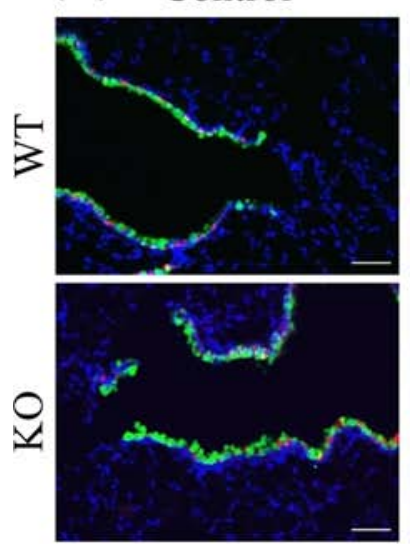

(B)

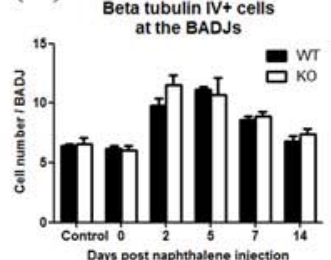

Day 2
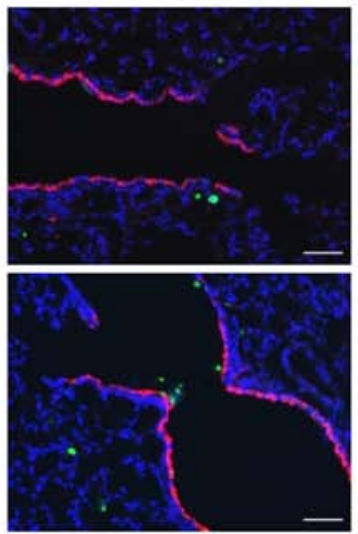

(C)

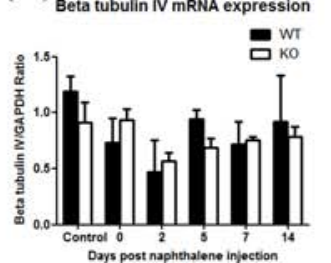

Day 7
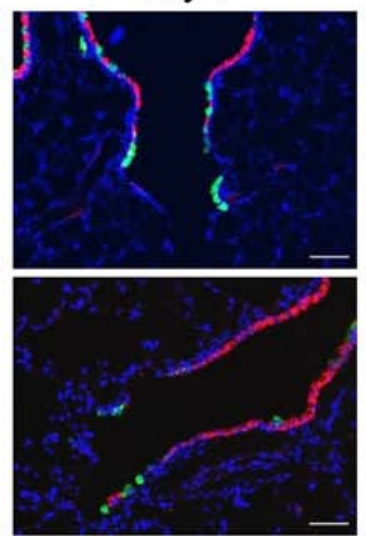

(D)

Foxj1 mRNA expression

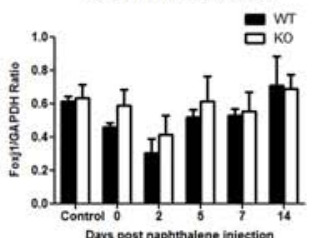

Day 14

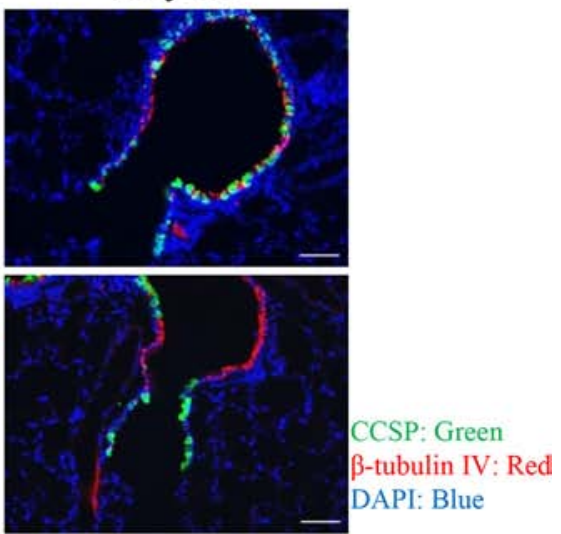

(E)

ccsp+ cells: beta tublin IV+ cells

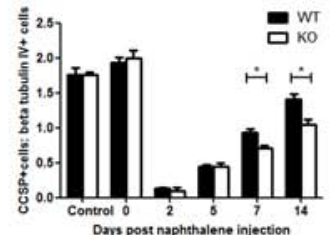

Figure 5: XB130 deficiency did not affect ciliated cells during small airway epithelial repair. A. Immunofluorescence study shows a dynamic change for Club cells (CCSP+, green) and ciliated epithelial cells ( $\beta$-tubulin IV+, red) after naphthalene challenge at the BADJs. Scale Bars $=50 \mu \mathrm{m}$. B. At day 2 and 5, the number of ciliated epithelial cells ( $\beta$-tubulin IV+) increased at the BADJs in both groups. C, D. The mRNA expressions of $\beta$-tubulin IV and Foxj1 (another ciliated cell marker) did not change over time. E. At day 7 and 14 after naphthalene treatment, the ratio of Club cells to ciliated epithelial cells was significantly lower in KO mice. $\left({ }^{*} p<0.05\right)$.

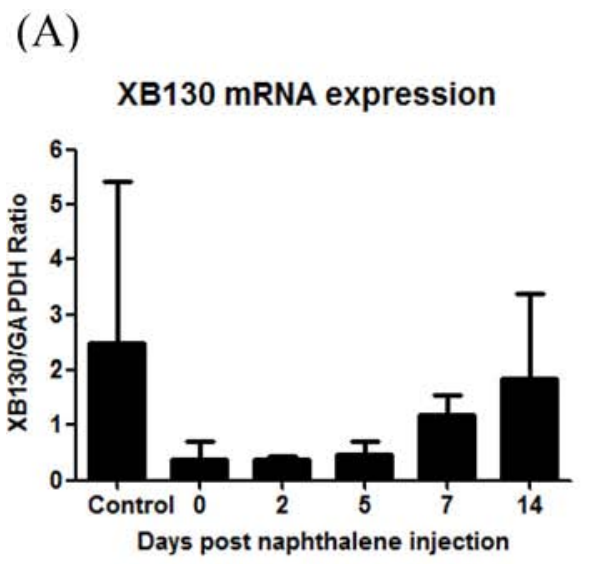

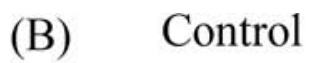
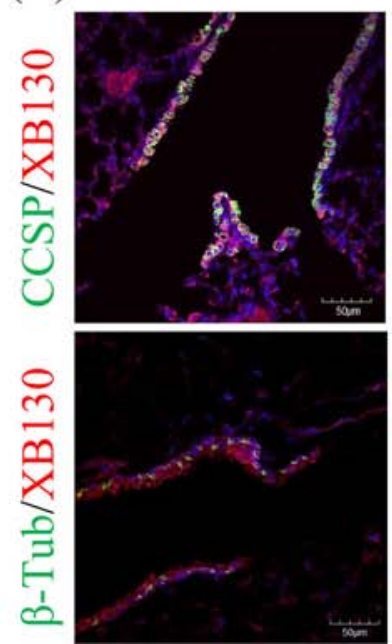

Day 2
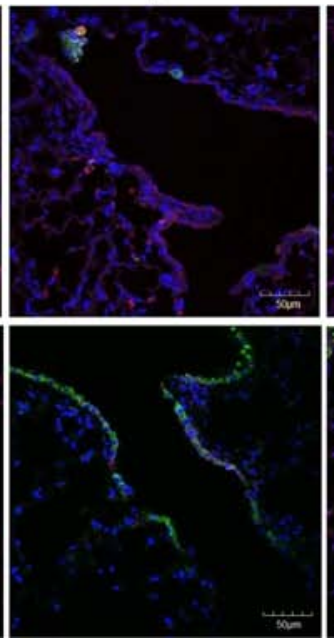

Day 14

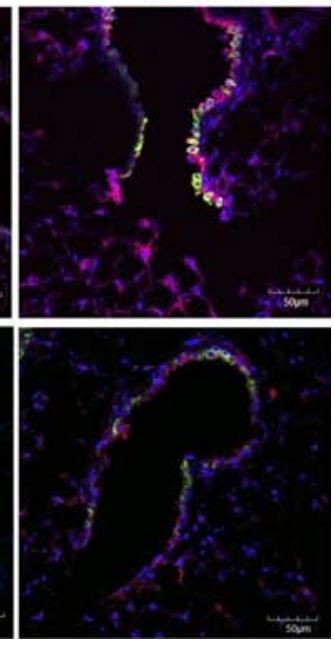

Figure 6: Expression of XB130 in Club cells but not in ciliated cells. A. $X B 130$ gene expression changes after naphthalene treatment in the lung tissues of WT mice, determined by RT-PCR. B. XB130 (red) was co-stained with CCSP (for Club cells, green), or with $\beta$-tubulin IV (for ciliated cells, green). The disappearance and reappearance of XB130 during injury and repair was associated with Club cells.

are found at this time point. In the untreated lungs, only the expression of 10 genes was significantly different in the KO mice compared to the WT mice. Of these, the top one is $X B 130$, as is expected for an $X B 130$ knock out. Seven days after the naphthalene challenge,
493 genes had significant expression differences compared to the untreated WT group (Figure 10A), and 414 genes compared to the KO group (Figure 10B). Of these, there were 254 gene transcripts in common between the KO and WT groups (Figure 10D). A larger 
(A) WT
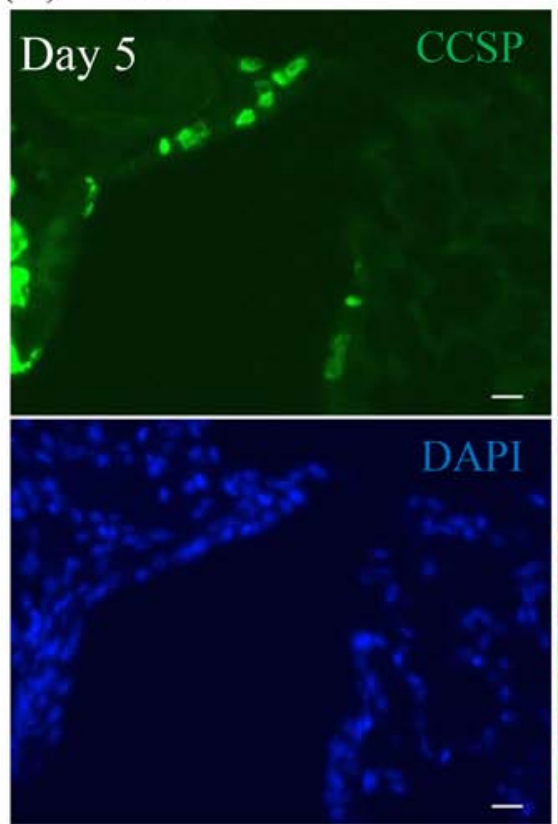
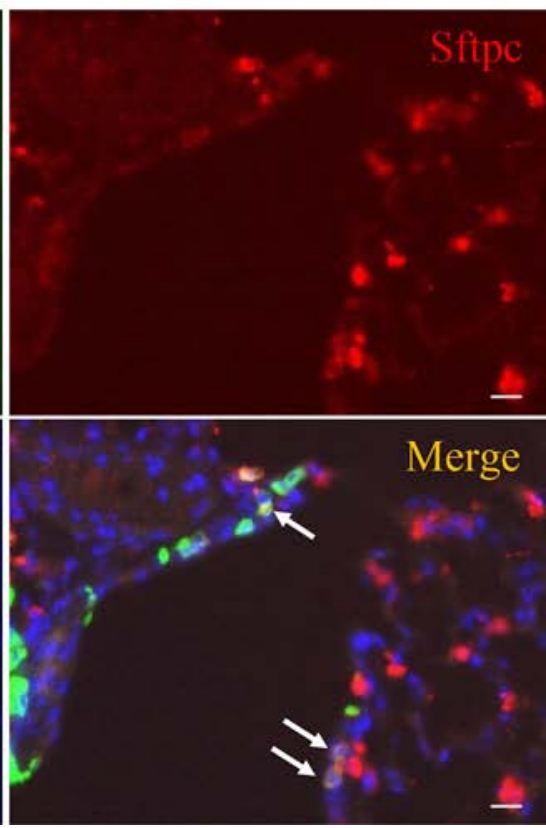

(B)

CCSP+/Sftpc+ cells at the BADJs

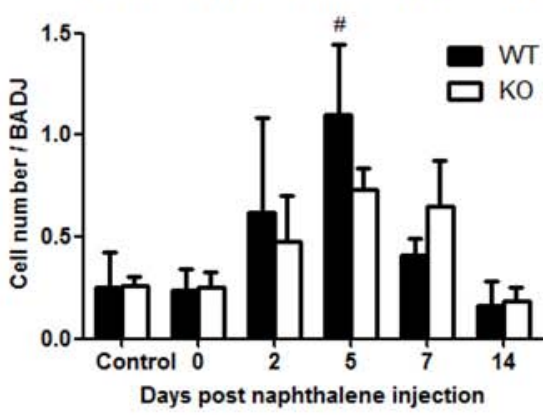

CCSP: Green

Sftpc: Red

DAPI: Blue

Figure 7: XB130 deficiency reduced bronchioalveolar stem cell proliferation during small airway epithelial repair. A. Immunofluorescence staining shows the localization of bronchioalveolar stem cells (BASCs; arrows, CCSP $+/ \mathrm{Sftpc}+$ ) at the BADJs at day 5 after naphthalene treatment in WT mice. Scale Bars $=20 \mu \mathrm{m}$. B. At day 5 , the number of BASCs was significantly increased in WT mice compared to control, day 0 and day 14 groups. The number of BASCs in KO mice was not significantly increased. (\#p $<0.05$ ).

proportion of genes showed increased expression in the naphthalene-treated group, especially in the WT-specific genes (Figure 10C) and those commonly regulated in both WT and KO groups (Figure 10D). By contrast, in the $\mathrm{KO}$-specific group, the number of up-regulated genes is similar to that of the down-regulated genes (Figure 10E).

The top molecular and cellular functions, as determined by IPA (Ingenuity Pathway Analysis), enriched by these differentially expressed genes in either the WT or KO groups were virtually the same (Table 1). The biological functions enriched in the top IPA interaction network for the WT group (Figure 11A) are: Cell Cycle, Cellular Assembly and Organization, DNA Replication, Recombination, and Repair, which are the same as in the top network for the KO group (Figure 11B). Among the top 25 regulated genes in the WT group, 14 of them were found in the KO group (Table 2).

We also directly compared the gene expression between KO and WT naphthalene treated animals: 60 genes were found to have significantly different expression levels (Figure 12A). The biological functions enriched by the top IPA generated interaction network (Figure 12B) are Tissue Morphology, Cell Mediated Immune Response and Cellular Development. A group of genes involved in inflammatory and immune responses are up-regulated in $\mathrm{KO}$ mice in comparison to those in WT mice, including CD163 (a member of the scavenger receptor cysteine-rich superfamily, expressed in monocytes and macrophages),
EDN1 (endothelin 1, a potent vasoconstrictor), FKBP5 (FK506 binding protein 5, which plays a role in immunoregulation), and HIF3A (hypoxia inducible factor 3, alpha subunit). Moreover, this network contains many interactions involving members of several intracellular signal transduction pathways, especially the PI3K/Akt pathway (Figure 12, highlighted by red circles), consistent with our observation of XB130 phosphorylation of members of this pathway (Figure 9).

To find pathways activated by naphthalene treatment that differ significantly in their activity between KO and WT mice, we performed a canonical pathway activation $\mathrm{z}$-score comparison in IPA of naphthalene treated vs. untreated mice in $\mathrm{KO}$ compared to WT groups. The canonical pathway that had the largest difference in predicted activation between $\mathrm{KO}$ and WT was Cyclins and Cell Cycle Regulation. Although this pathway was predicted to be activated in both groups, it was predicted to have higher activity in WT compared to $\mathrm{KO}$ mice.

Expression of multiple cyclins and CDK1 (cyclindependent kinase 1) were significantly upregulated in both groups. However, CDKN1A (cyclin-dependent kinase inhibitor 1A (p21, Cip1) and WEE1 (WEE1 G2 checkpoint kinase) were only significantly increased in the KO group (Table 3). IPA's Molecule Activity Predictor suggests that upregulation of p21 and WEE1 can inhibit cell cycle progression at G1, S and G2 phases (Figure E2 in the online data supplement), which may help to explain 
(A)

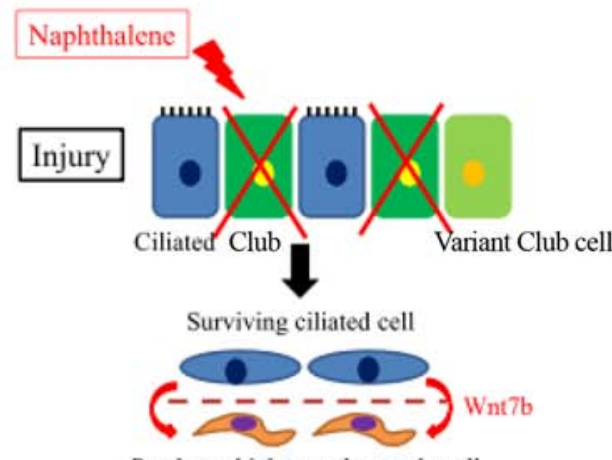

Parabronchial smooth muscle cell
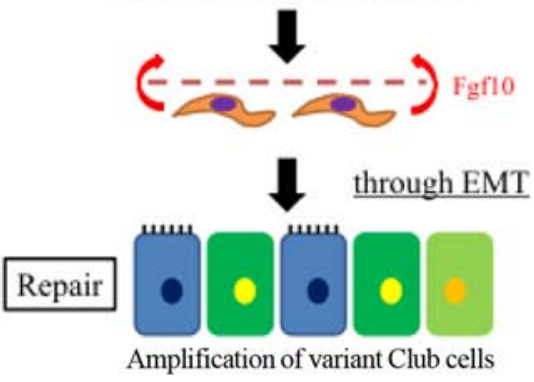

(B)

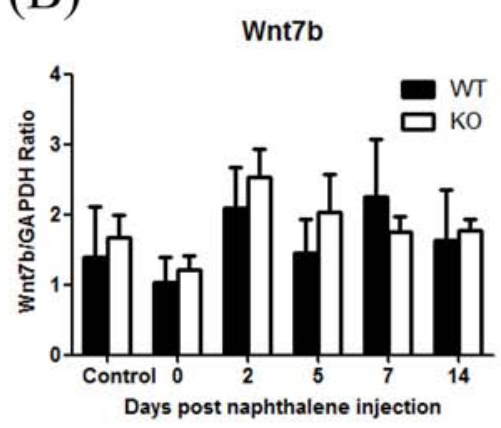

(D)

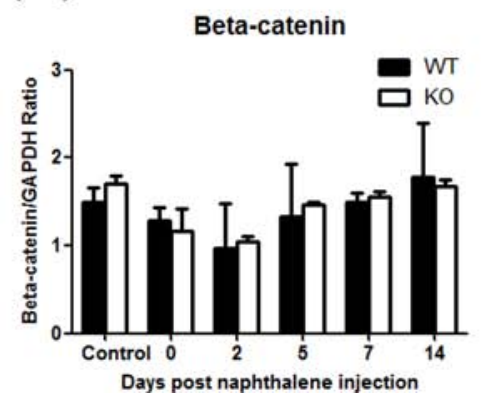

(C)

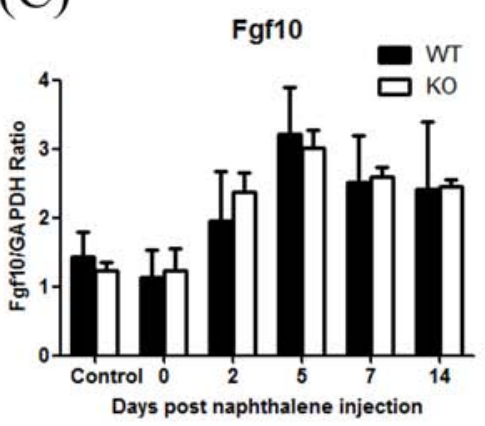

(E)

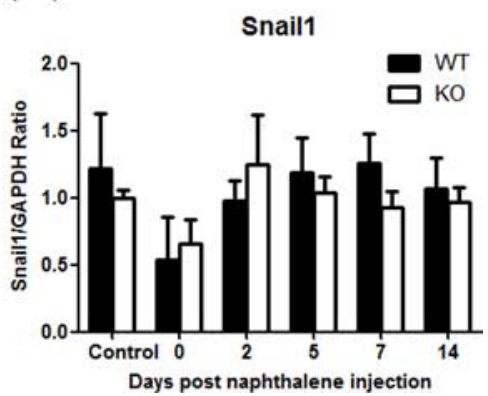

Figure 8: XB130 deficiency did not affect expression of genes related to paracrine-induced epithelial mesenchymal transition (EMT) during small airway epithelial repair. A. The Schema shows a paracrine regulation between surviving variant Club cells (as local stem cells) and parabronchial smooth muscle cells that promote EMT during airway epithelial repair after naphthalene challenge. B-E. The mRNA expression levels on 4 related genes (Wnt7b, Fgf10, $\beta$-catenin and Snail1) were not significantly different between WT and KO mice.

Table 1: WT and KO groups share the same top molecular and cellular functions (determined from IPA) of gene expression changes in the lung, induced by naphthalene at day 7.

\begin{tabular}{|c|c|c|c|c|c|c|}
\hline \multirow{2}{*}{$\begin{array}{l}\text { Molecular and Cellular } \\
\text { Functions }\end{array}$} & \multicolumn{3}{|c|}{ WT } & \multicolumn{3}{|c|}{ KO } \\
\hline & $p$-value & \# Molecules & Rank & $p$-value & \# Molecules & Rank \\
\hline Cell Cycle & $1.08 \mathrm{E}-23-4.26 \mathrm{E}-03$ & 96 & 1 & 2.73E-25-2.47E-03 & 99 & 1 \\
\hline $\begin{array}{l}\text { Cellular Assembly and } \\
\text { Organization }\end{array}$ & $1.08 \mathrm{E}-23-4.26 \mathrm{E}-03$ & 59 & 2 & 2.73E-25-2.47E-03 & 83 & 2 \\
\hline $\begin{array}{l}\text { DNA Replication, } \\
\text { Recombination, and } \\
\text { Repair }\end{array}$ & $1.08 \mathrm{E}-23-4.26 \mathrm{E}-03$ & 52 & 3 & 2.73E-25-2.03E-03 & 73 & 3 \\
\hline Cellular Movement & $1.11 \mathrm{E}-10-1.31 \mathrm{E}-03$ & 26 & 4 & $2.06 \mathrm{E}-12-2.27 \mathrm{E}-03$ & 94 & 4 \\
\hline $\begin{array}{l}\text { Cellular Function and } \\
\text { Maintenance }\end{array}$ & $3.41 \mathrm{E}-07-4.26 \mathrm{E}-03$ & 29 & 5 & 7.85E-09-2.27E-03 & 90 & 6 \\
\hline Cell Death and Survival & $8.15 \mathrm{E}-07-3.96 \mathrm{E}-03$ & 119 & 6 & $2.22 \mathrm{E}-10-1.26 \mathrm{E}-03$ & 125 & 5 \\
\hline
\end{tabular}


why XB130 deficiency delays cell proliferation and repair.

\section{DISCUSSION}

Proliferation of BASCs and epithelial cells after injury is crucial for bronchial epithelial repair and regeneration. In this study, we showed that the presence of XB130 in bronchial Club cells promotes proliferation of BASCs and Club cells in the small airways during the repair process after naphthalene challenge. These functions are likely mediated through the PI3K/Akt pathway. Moreover, microarray data suggest that XB130 deficiency may cause activation of p21 and WEE1 related inhibition of cell cycle progression and cell proliferation.

At the early injury phase, cell death score and TUNEL assay did not show significant differences between WT and XB130 KO mice. Naphthalene induces severe death of Club cells [3-5]. The presence of XB130 in Club cells may have limited protective effects on cell survival. It will be interesting to see under other pathological conditions, such as sepsis, ventilator-induced lung injury, cigarette smoking, air pollution, or allergic responses, whether XB130 would have protective effects on cell survival.

On the other hand, at days 7 and 14, which is the repair phase, $\mathrm{H} \& \mathrm{E}$ staining showed that recovery of injured bronchial epithelium was delayed in XB130 KO mice. Moreover, in $\mathrm{KO}$ mice, the total cell numbers at the BADJs, the number of Club cells, and the ratio of $\mathrm{CCSP}+$ to $\beta$-tubulin IV+ cells were also significantly lower. XB130 was mainly found in the CCSP+ cells, not in the ciliated cells. Therefore, XB130 deficiency mainly affected proliferation of Club cells.

Migration of surviving cells after injury is the initial response to cover the wound in airway epithelial repair [1]. Park et al. studied the behavior of ciliated cells after naphthalene treatment, and showed that epithelial integrity was initially maintained by extension and migration of squamous cells in a process that proceeded cell proliferation [25]. Kida et al. indicated that cell migration was involved in the airway epithelial repair process [23]. XB130 was involved in cell migration through Rac- and cytoskeletal-dependent mechanisms [14]. In the present study, however, we did not see significant differences in terms of cell spreading and migration. IF staining showed that XB130 was not stained in ciliated cells in WT mice. Therefore, the absence of XB130 may not affect the spreading and migration of ciliated cells. We have recently studied the role of XB130 in large airway epithelial repair and regeneration with an isogenic murine tracheal transplant model, and we found that the major function of $\mathrm{XB} 130$ in trachea is to influence the differentiation of the airway epithelium [20]. It is possible that the same protein may play different roles in different cell types based on its expression levels and the differentiation status of the cells.

Variant Club cells are progenitor cells located at the BADJs that proliferate and differentiate into regular Club cells after airway epithelial injury [6]. Regenerating Club cells may give rise to cell types resembling those seen in normal bronchioles [31]. At day 5, in WT mice, the number of BASCs was significantly higher than at days 0
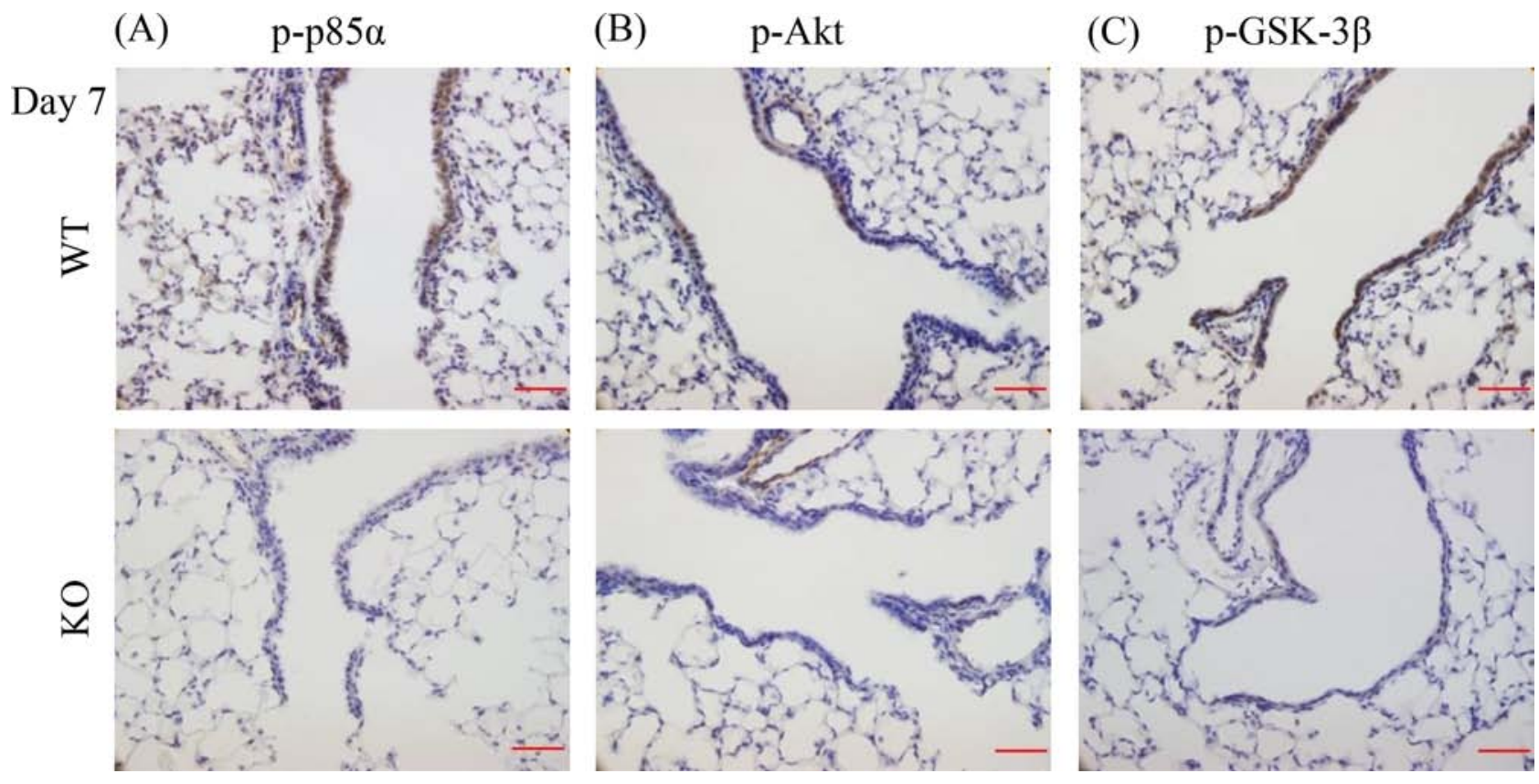

Figure 9: XB130 deficiency reduced phosphorylation of molecules on PI3K/Akt cascade during small airway epithelial repair. A-C. Immunohistochemistry staining (brown) for p-p85 (regulatory submit of PI3K), p-Akt and p-GSK-3 $\beta$ at day 7 after naphthalene treatment in airway epithelial cells was seen strongly in WT mice but not in KO mice. Scale Bars $=50 \mu \mathrm{m}$. 


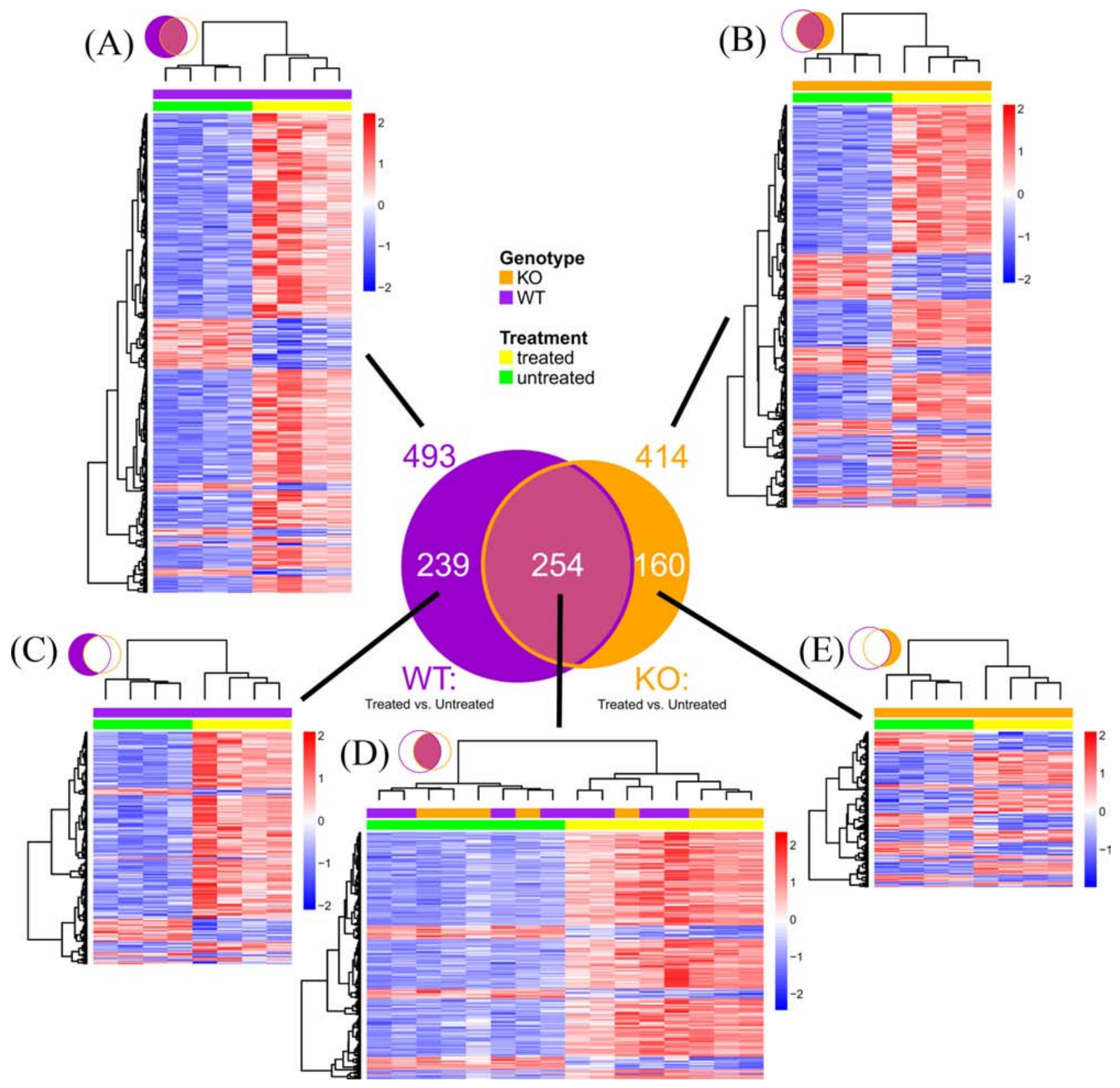

Figure 10: Microarray mouse lung gene expression profile 7 days after naphthalene or no treatment. Venn diagram summarizes number of genes with significant expression differences (Fold $\geq 1.5$, FDR $\leq 0.05$ ) at day 7 between naphthalene treated and untreated mice ( $n=4$ per group). Purple circle: WT mice. Orange circle: KO mice. A-E. Hierarchical clustering heatmaps show relative expression differences for each gene represented in the Venn diagram. Rows represent genes. Columns represent mouse samples. Gene expression is z-score normalized across rows, where low, mean, and high expression levels are represented by blue, white and red, respectively. Color bars above columns indicate genotype (KO: orange, WT: purple) and naphthalene treatment (treated: yellow, untreated: green). (A) All significant genes in WT. (B) All significant genes in KO. (C) Significant genes in WT but not significant in KO. (D) Genes significant in both WT and KO. (E) Significant genes in KO but not significant in WT.

and14 and in the control group. In XB130 KO mice, even though the number of BASCs was also increased at days 5 and 7 , there were no significant differences among time points. Furthermore, at day 5, the number of proliferative (Ki-67+) epithelial cells was significantly lower in KO mice. Thus, the slowdown of the airway epithelial repair and regeneration in XB130 may be due to less proliferation of BASCs at BADJs.
In the present study, there was much less staining of p-p85 $\alpha, \mathrm{p}$-Akt and p-GSK-3 $\beta$ in airway epithelial cells in XB130 KO mice at day 7. The PI3K/Akt pathway can further regulate $\beta$-catenin in airway epithelial repair after naphthalene treatment [30]. Akt can inhibit GSK-3 $\beta$, therefore preventing the degradation of $\beta$-catenin. Akt can also phosphorylate $\beta$-catenin directly on Ser552 for its translocation to the nucleus [32]. Therefore, reduced 
Table 2: Similarity of top 25 genes regulated by naphthalene treatment at day 7 between WT and KO groups.

\begin{tabular}{|c|c|c|c|c|c|c|c|}
\hline \multicolumn{4}{|c|}{ WT } & \multicolumn{4}{|c|}{ KO } \\
\hline $\begin{array}{l}\text { Gene } \\
\text { Symbol }\end{array}$ & Entrez ID & Fold & FDR & Gene Symbol & Entrez ID & Fold & FDR \\
\hline Clcal & 23844 & 27.219 & 0.00010 & Clcal & 23844 & 45.604 & 0.00003 \\
\hline Agr2 & 23795 & 7.942 & 0.00015 & Chil4 & 104183 & 29.363 & 0.01534 \\
\hline Fgg & 99571 & 7.192 & 0.00007 & Agr2 & 23795 & 8.171 & 0.00012 \\
\hline Muc5ac & 17833 & 5.142 & 0.00583 & Cd177 & 68891 & 7.281 & 0.00003 \\
\hline Gp2 & 67133 & 4.911 & 0.00019 & Retnla & 57262 & 5.324 & 0.00011 \\
\hline Retnla & 57262 & 4.788 & 0.00016 & Igkv5-43 & 381783 & -5.238 & 0.00643 \\
\hline Tff2 & 21785 & 4.784 & 0.00323 & Muc5ac & 17833 & 5.049 & 0.00701 \\
\hline Reg3g & 19695 & 4.016 & 0.00911 & Ghrl & 58991 & 4.906 & 0.00001 \\
\hline Ighv1-34 & 628614 & -3.987 & 0.01838 & Fgg & 99571 & 4.545 & 0.00033 \\
\hline Cd177 & 68891 & 3.897 & 0.00036 & Gp2 & 67133 & 4.362 & 0.00027 \\
\hline Slc26a4 & 23985 & 3.812 & 0.00255 & Igkv6-14 & 667881 & -4.055 & 0.04842 \\
\hline Cdk1 & 12534 & 3.643 & 0.00010 & Igkv9-124 & 243431 & -3.883 & 0.00417 \\
\hline Muc5b & 74180 & 3.562 & 0.00280 & Fmo3 & 14262 & -3.879 & 0.00047 \\
\hline Mfsd2a & 76574 & 3.491 & 0.00013 & Slc26a4 & 23985 & 3.824 & 0.00273 \\
\hline Sptssb & 66183 & 3.426 & 0.00022 & Fkbp5 & 14229 & 3.793 & 0.00018 \\
\hline Fcgbp & 215384 & 3.360 & 0.04863 & Fcgbp & 215384 & 3.787 & 0.03450 \\
\hline Saa3 & 20210 & 3.320 & 0.02606 & Cdk1 & 12534 & 3.781 & 0.00007 \\
\hline Ghrl & 58991 & 3.265 & 0.00007 & Sptssb & 66183 & 3.630 & 0.00014 \\
\hline Ccnal & 12427 & 3.192 & 0.00006 & Pbk & 52033 & 3.567 & 0.00025 \\
\hline Ect2 & 13605 & 3.140 & 0.00015 & 9530077C05Rik & 68283 & 3.491 & 0.00006 \\
\hline $\mathrm{Pbk}$ & 52033 & 3.138 & 0.00054 & Zbtb16 & 235320 & 3.446 & 0.00673 \\
\hline Top2a & 21973 & 3.102 & 0.00016 & Fabp1 & 14080 & -3.367 & 0.00070 \\
\hline Oit1 & 18300 & 3.043 & 0.00527 & Mfsd2a & 76574 & 3.344 & 0.00013 \\
\hline Prc1 & 233406 & 3.035 & 0.00055 & Pla2g4c & 232889 & 3.318 & 0.02976 \\
\hline $\mathrm{BC} 048546$ & 232400 & 2.972 & 0.04711 & Ccna2 & 12428 & 3.309 & 0.00029 \\
\hline
\end{tabular}

Underline indicates common genes for WT and KO. Italic indicates decreased expression in treated vs. untreated mice

phosphorylation of PI3K/Akt/GSK-3 $\beta$ in Club cells may affect cell proliferation and airway repair and regeneration. Our microarray/bioinformatics study further supports the involvement of the PI3K/Akt pathway in XB130 related cellular responses (Figure 12).

The microarray data also suggested more inflammatory activities in the $\mathrm{KO}$ mice. The naphthaleneinduced expression of CDKN1A (p21, Cip1) and WEE1 was only up-regulated in the $\mathrm{KO}$ mice, which may inhibit cell proliferation and cell cycle progression (Figure E2), and subsequently delay repair and regeneration of airway epithelial cells. Because whole lung RNA was used for microarray analysis, we cannot specify which cell type(s) are responsible for the major observed changes in gene expression. However, this analysis helps to determine the overall changes of gene expression in the lung. The changes that we highlighted are consistent with our other studies.

In conclusion, our results indicate that XB130 is involved in BASC and Club cell proliferation. We speculate that this function is mainly mediated through the phosphorylation of PI3K/Akt/GSK-3 $\beta$ and related signaling events. Clinically relevant models related to small airway diseases should be used to further explore the 

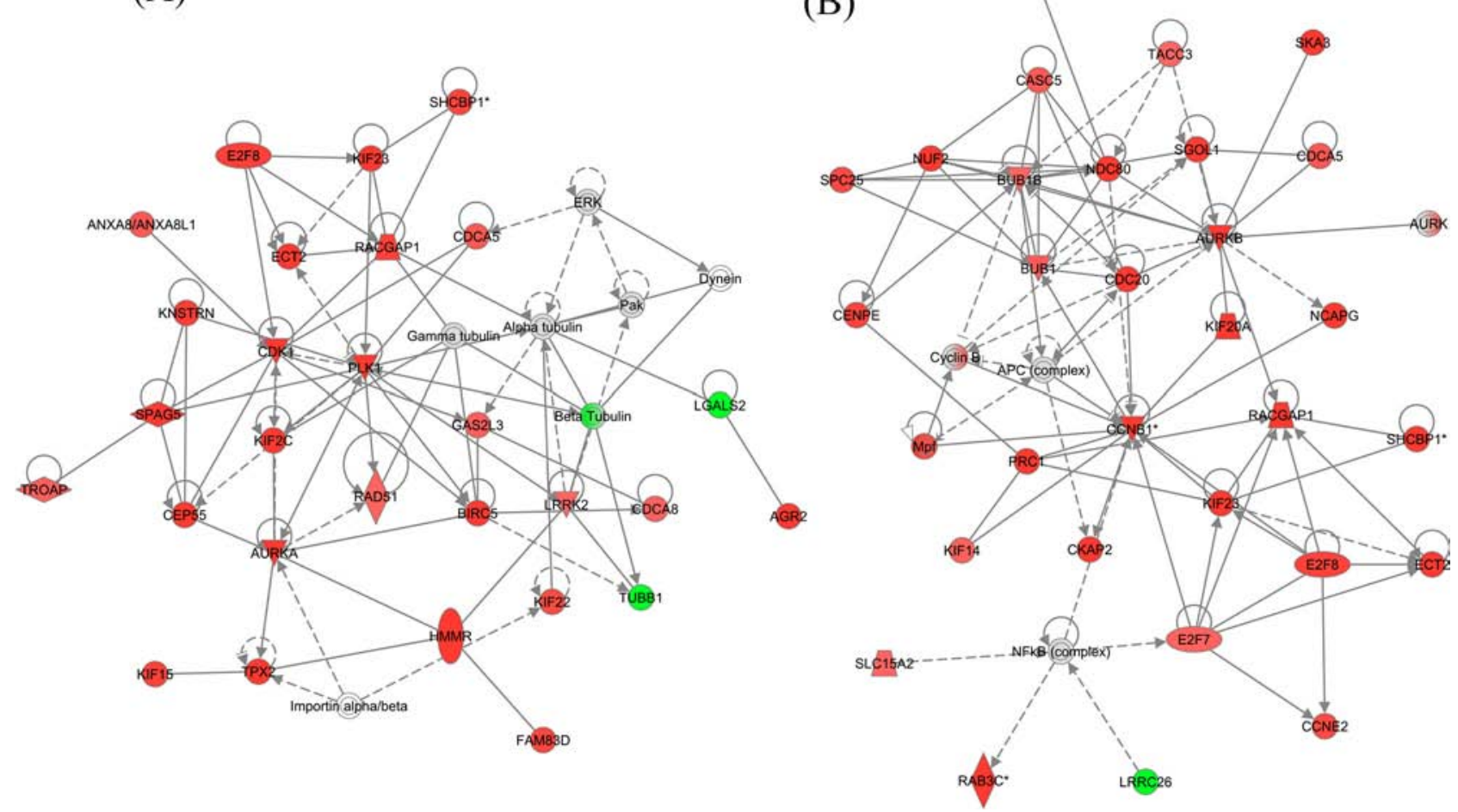

Figure 11: The top IPA generated interaction network of naphthalene-induced genes in (A) WT and (B) KO mice. These networks are enhanced for Cell Cycle, Cellular Assembly and Organization, DNA Replication, Recombination, and Repair functions. Red: up-regulation (treated relative to untreated). Green: down-regulation. Gray: does not meet cutoff values for significance. White: not present on microarray. Nodes with a single border represent individual components (at gene or protein level). Nodes with a double border represent families of related components and/or complexes containing multiple individual components. Double bordered nodes may have a mixture of different colors due to different microarray expression levels for each of their individual components. Colors represent microarray determined RNA expression levels.

role of XB130 in airway epithelial repair, regeneration and remodeling. Moreover, the role of XB130 in airway repair should be addressed directly in human lung diseases.

\section{MATERIALS AND METHODS}

More detailed materials and methods are presented as online Supplementary Materials.

\section{Animal care}

The study protocol was approved by Animal Use and Care Committee of the University Health Network. All animals received humane care in compliance with the Guide for the Care and Use of Experimental Animals formulated by the Canadian Council on Animal Care.

XB130 KO mice were generated in collaboration with Dr. Tak W. Mak (University of Toronto), and backcrossed more than 10 generations on a C57BL/6 genetic background. XB130 KO mice showed a normal life span, and did not have obvious phenotypes in a series of physiological tests compared to their wild-type (WT) littermates [20].

\section{Naphthalene treatment}

Female XB130 KO mice and their female WT littermates ( 8 - 12 weeks of age) were either treated with naphthalene (Sigma-Aldrich, St. Louis, MO) dissolved in corn oil (Sigma-Aldrich) at a dose of $200 \mathrm{mg} / \mathrm{kg}$ body weight intraperitoneally, or were untreated. Mice were sacrificed at days $0,2,5,7$ and 14 after treatment. Corn oil alone $(0.25 \mathrm{ml} / \mathrm{kg})$ was administered to a control group, where mice were sacrificed at day 2 after corn oil treatment [33]. For each time point, 4 - 6 mice were used per group. Lung tissues were collected for subsequent studies.

\section{Histological study}

The left lung tissue sections were stained with hematoxylin and eosin (H\&E). Cell death was determined semi-quantitatively from 10 randomly chosen terminal 

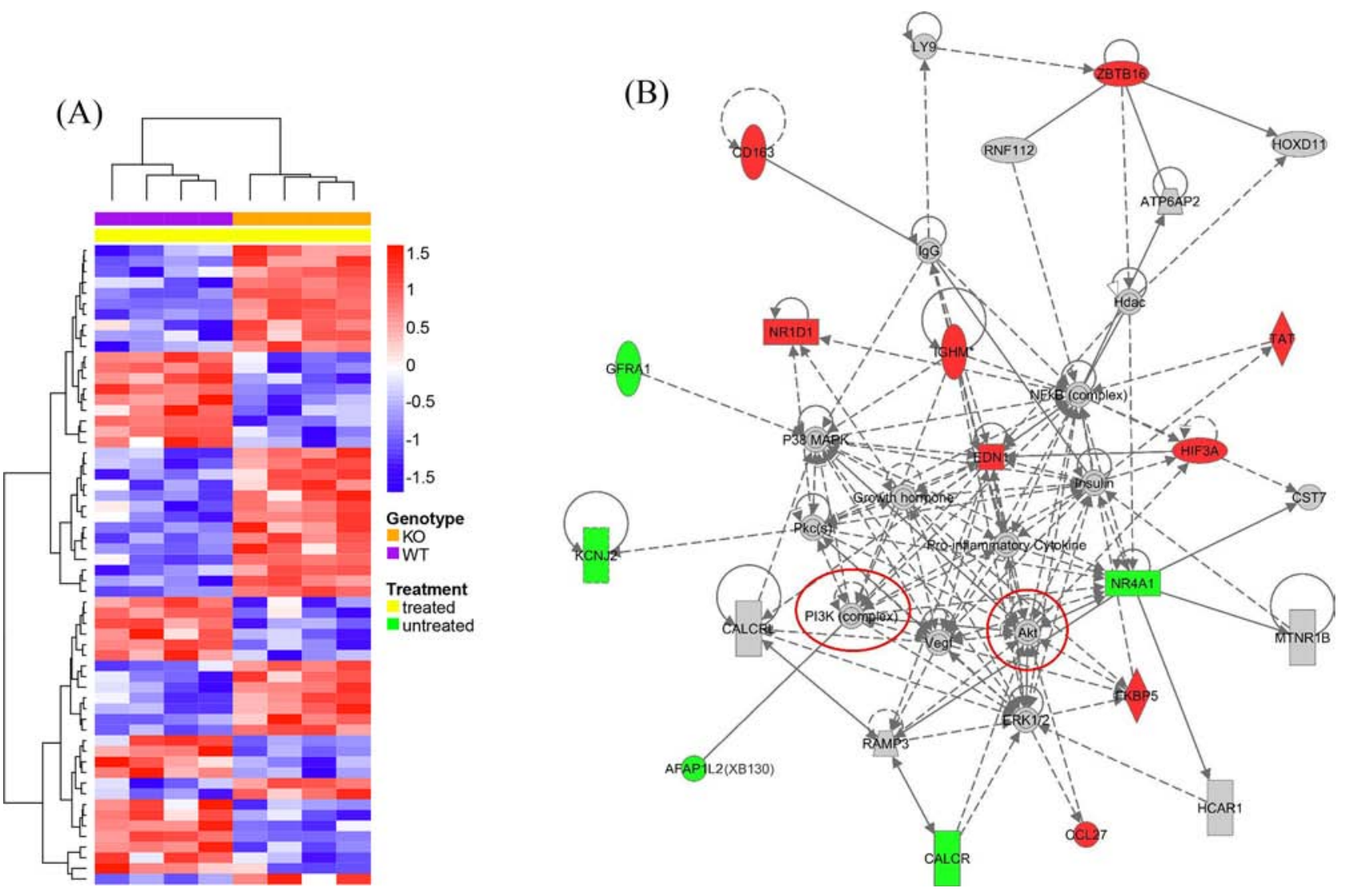

Figure 12: Microarray determined gene expression differences between KO and WT mice 7 days after naphthalene treatment. A. Hierarchical clustering heatmap shows relative expression differences for each of 60 genes with significant expression differences between KO and WT mice 7 days after naphthalene treatment. See details in Figure 10 legends. B. The PI3K/Akt signal pathway is related to genes differentially expressed between KO and WT mice in the lung 7 days after naphthalene treatment, as shown by the top IPA generated interaction network. The biological functions enriched by the molecules in this network are Tissue Morphology, Cell Mediated Immune Response and Cellular Development. Red: up-regulation (KO relative to WT). Green: down-regulation. Red circles: PI3K/Akt pathway components are highlighted. See Figure 11 legend for other details.

bronchi (x400) [33]. Epithelial damage was expressed as a ratio between denuded and total surface within the BADJ $(200 \mu \mathrm{m})$ [6]. ImageJ (1.46r) (NIH, Bethesda, MD) was used for data analyses.

\section{Immunohisotochemistory (IHC) and immunofluorescence (IF)}

The primary antibodies used are shown in Table E1 (in the online data supplement). IHC was performed using a Vectastain ABC kit (Vector Laboratories, Burlington, ON). All fluorescent staining was performed with appropriate secondary antibodies from Invitrogen and mounted with Prolong Gold Antifade Mountant with DAPI $^{\circledR}$ (Invitrogen, Burlington, ON). Positive cells were counted from at least 5 BADJs $(x 400)$.

\section{TUNEL assay}

Terminal transferase dUTP nick end labelling (TUNEL) was performed with In Situ Cell Death Detection Kit, TMR red (Roche, Penzberg, Germany). We randomly chose at least 10 fields (x400) per slide to quantify TUNEL+ epithelial cells attached on basement membrane, expressed as percentage of total DAPI+ cells [34].

\section{Quantitative RT-PCR}

Total RNA was extracted from the right lung. Quantitative RT-PCR was performed [17]. PCR primers are shown in Table E2 (in the online data supplement).

\section{Microarray}

Lung tissue RNA from day 7 after naphthalene treatment or from untreated WT and KO mice ( $n=4$ /group) were used with Mouse Gene ST 2.0 chips (Affymetrix, Santa Clara, CA) and microarray data were analyzed as described [35]. See details in the online supplement.

\section{Statistical analysis}

All values are expressed as mean \pm standard deviation (SD). Statistical analyses were performed by 
Table 3: Naphthalene-induced gene expression changes in the pathway of Cyclins and Cell Cycle Regulation are similar between the KO and WT groups, except for CDKN1A and WEE1, which are significantly upregulated only in the KO group.

\begin{tabular}{llccccc}
\hline \multirow{2}{*}{ Gene symbol } & \multirow{2}{*}{ Gene name } & \multicolumn{2}{c}{ KO } & & \multicolumn{2}{c}{ WT } \\
\cline { 3 - 4 } \cline { 6 - 7 } & & Fold change & FDR & & Fold change & FDR \\
\hline CCNA1 & cyclin A1 & 2.310 & $2.93 \mathrm{E}-03$ & & 3.168 & $8.72 \mathrm{E}-04$ \\
\hline CCNA2 & cyclin A2 & 3.057 & $3.69 \mathrm{E}-03$ & & 2.404 & $1.08 \mathrm{E}-02$ \\
\hline CCNB1 & cyclin B1 & 2.494 & $2.49 \mathrm{E}-02$ & & 2.068 & $4.87 \mathrm{E}-03$ \\
\hline CCNB2 & cyclin B2 & 2.510 & $4.45 \mathrm{E}-03$ & & 2.272 & $7.31 \mathrm{E}-03$ \\
\hline CCNE2 & cyclinE2 & 1.808 & $5.67 \mathrm{E}-03$ & & 1.647 & $1.14 \mathrm{E}-02$ \\
\hline CDK1 & $\begin{array}{l}\text { cyclin-dependent } \\
\text { kinase1 }\end{array}$ & 3.419 & $1.41 \mathrm{E}-03$ & & 3.409 & $1.64 \mathrm{E}-03$ \\
\hline CDKN1A & $\begin{array}{l}\text { cyclin-dependent } \\
\text { kinaseinhibitor 1A } \\
\text { (p21, Cip1) }\end{array}$ & 1.524 & $4.35 \mathrm{E}-02$ & & 1.294 & $2.08 \mathrm{E}-01$ \\
\hline WEE1 & $\begin{array}{l}\text { WEE1 G2 } \\
\text { checkpoint kinase }\end{array}$ & 1.604 & $7.75 \mathrm{E}-03$ & & 1.195 & $2.63 \mathrm{E}-01$ \\
\hline
\end{tabular}

using Student's $t$-test and analysis of variance (ANOVA) with GraphPad Prism 5.0 (GraphPad, La Jolla, CA). $p<0.05$ was considered to be statistically significant.

\section{CONFLICTS OF INTEREST}

No conflicts of interest, financial or otherwise are declared by the authors.

\section{GRANT SUPPORT}

This work was supported by the Canadian Institutes of Health Research (CIHR) operating grants MOP-13270, MOP-42546 and MOP-119514.

\section{Editorial note}

This paper has been accepted based in part on peerreview conducted by another journal and the authors' response and revisions as well as expedited peer-review in Oncotarget.

\section{REFERENCES}

1. Xiao H, Li DX, Liu M. Knowledge translation: airway epithelial cell migration and respiratory diseases. Cell Mol Life Sci. 2012; 69:4149-4162.

2. Plopper CG, Hill LH, Mariassy AT. Ultrastructure of the nonciliated bronchiolar epithelial (Clara) cell of mammalian lung. III. A study of man with comparison of 15 mammalian species. Exp Lung Res. 1980; 1:171-180.
3. Buckpitt A, Buonarati M, Avey LB, Chang AM, Morin D, Plopper CG. Relationship of cytochrome P450 activity to Clara cell cytotoxicity. II. Comparison of stereoselectivity of naphthalene epoxidation in lung and nasal mucosa of mouse, hamster, rat and rhesus monkey. J Pharmacol Exp Ther. 1992; 261:364-372.

4. Stripp BR, Maxson K, Mera R, Singh G. Plasticity of airway cell proliferation and gene expression after acute naphthalene injury. Am J Physiol. 1995; 269:L791-799.

5. Van Winkle LS, Isaac JM, Plopper CG. Distribution of epidermal growth factor receptor and ligands during bronchiolar epithelial repair from naphthalene-induced Clara cell injury in the mouse. Am J Pathol. 1997; 151:443-459.

6. Giangreco A, Reynolds SD, Stripp BR. Terminal bronchioles harbor a unique airway stem cell population that localizes to the bronchoalveolar duct junction. Am J Pathol. 2002; 161:173-182.

7. Rawlins EL, Hogan BL. Epithelial stem cells of the lung: privileged few or opportunities for many?. Development. 2006; 133:2455-2465.

8. Kim CF, Jackson EL, Woolfenden AE, Lawrence S, Babar I, Vogel S, Crowley D, Bronson RT, Jacks T. Identification of bronchioalveolar stem cells in normal lung and lung cancer. Cell. 2005; 121:823-835.

9. Yang Y, Iwanaga K, Raso MG, Wislez M, Hanna AE, Wieder ED, Molldrem JJ, Wistuba II, Powis G, Demayo FJ, Kim CF, Kurie JM. Phosphatidylinositol 3-kinase mediates bronchioalveolar stem cell expansion in mouse models of oncogenic K-ras-induced lung cancer. PLoS One. 2008; 3:e2220.

10. Tiozzo C, De Langhe S, Yu M, Londhe VA, Carraro G, Li M, Li C, Xing Y, Anderson S, Borok Z, Bellusci S, 
Minoo P. Deletion of Pten expands lung epithelial progenitor pools and confers resistance to airway injury. Am J Respir Crit Care Med. 2009; 180:701-712.

11. Xu J, Bai XH, Lodyga M, Han B, Xiao H, Keshavjee S, Hu J, Zhang H, Yang BB, Liu M. XB130, a novel adaptor protein for signal transduction. J Biol Chem. 2007; 282:16401-16412.

12. Lodyga M, De Falco V, Bai XH, Kapus A, Melillo RM, Santoro M, Liu M. XB130, a tissue-specific adaptor protein that couples the RET/PTC oncogenic kinase to PI 3-kinase pathway. Oncogene. 2009; 28:937-949.

13. Shiozaki A, Shen-Tu G, Bai X, Iitaka D, De Falco V, Santoro M, Keshavjee S, Liu M. XB130 mediates cancer cell proliferation and survival through multiple signaling events downstream of Akt. PLoS One. 2012; 7:e43646.

14. Lodyga M, Bai XH, Kapus A, Liu M. Adaptor protein $\mathrm{XB130}$ is a Rac-controlled component of lamellipodia that regulates cell motility and invasion. J Cell Sci. 2010; 123:4156-4169.

15. Shi M, Huang W, Lin L, Zheng D, Zuo Q, Wang L, Wang N, Wu Y, Liao Y, Liao W. Silencing of XB130 is associated with both the prognosis and chemosensitivity of gastric cancer. PLoS One. 2012; 7:e41660.

16. Shiozaki A, Kosuga T, Ichikawa D, Komatsu S, Fujiwara H, Okamoto K, Iitaka D, Nakashima S, Shimizu H, Ishimoto T, Kitagawa M, Nakou Y, Kishimoto M, Liu M, Otsuji E. $\mathrm{XB130}$ as an independent prognostic factor in human esophageal squamous cell carcinoma. Ann Surg Oncol. 2013; 20:3140-3150.

17. Shiozaki A, Lodyga M, Bai XH, Nadesalingam J, Oyaizu T, Winer D, Asa SL, Keshavjee S, Liu M. XB130, a novel adaptor protein, promotes thyroid tumor growth. Am J Pathol. 2011; 178:391-401.

18. Bai XH, Cho HR, Moodley S, Liu M. XB130-A Novel Adaptor Protein: Gene, Function, and Roles in Tumorigenesis. Scientifica (Cairo). 2014; 2014:903014.

19. Shiozaki A, Liu M. Roles of XB130, a novel adaptor protein, in cancer. J Clin Bioinforma. 2011; 1:10.

20. Zhao J, Wang Y, Wakeham A, Hao Z, Toba H, Bai X, Keshavjee S, Mak TW, Liu M. XB130 deficiency affects tracheal epithelial differentiation during airway repair. PLoS One. 2014; 9:e108952.

21. Wu Q, Nadesalingam J, Moodley S, Bai X, Liu M. XB130 translocation to microfilamentous structures mediates NNKinduced migration of human bronchial epithelial cells. Oncotarget. 2015; 6:18050-65.

22. Verschoyle RD, Martin J, Dinsdale D. Selective inhibition and induction of CYP activity discriminates between the isoforms responsible for the activation of butylated hydroxytoluene and naphthalene in mouse lung. Xenobiotica. 1997; 27:853-864.

23. Kida H, Mucenski ML, Thitoff AR, Le Cras TD, Park KS, Ikegami M, Muller W, Whitsett JA. GP130-STAT3 regulates epithelial cell migration and is required for repair of the bronchiolar epithelium. Am J Pathol. 2008; 172:1542-1554.

24. Oliver JR, Kushwah R, Wu J, Pan J, Cutz E, Yeger H, Waddell TK, Hu J. Elf3 plays a role in regulating bronchiolar epithelial repair kinetics following Clara cell-specific injury. Lab Invest. 2011; 91:1514-1529.

25. Park KS, Wells JM, Zorn AM, Wert SE, Laubach VE, Fernandez LG, Whitsett JA. Transdifferentiation of ciliated cells during repair of the respiratory epithelium. Am J Respir Cell Mol Biol. 2006; 34:151-157.

26. Hegab AE, Nickerson DW, Ha VL, Darmawan DO, Gomperts BN. Repair and regeneration of tracheal surface epithelium and submucosal glands in a mouse model of hypoxic-ischemic injury. Respirology. 2012; 17:1101-1113.

27. Hegab AE, Ha VL, Gilbert JL, Zhang KX, Malkoski SP, Chon AT, Darmawan DO, Bisht B, Ooi AT, Pellegrini M, Nickerson DW, Gomperts BN. Novel stem/progenitor cell population from murine tracheal submucosal gland ducts with multipotent regenerative potential. Stem Cells. 2011; 29:1283-1293.

28. Zhang Y, Goss AM, Cohen ED, Kadzik R, Lepore JJ, Muthukumaraswamy K, Yang J, DeMayo FJ, Whitsett JA, Parmacek MS, Morrisey EE. A Gata6-Wnt pathway required for epithelial stem cell development and airway regeneration. Nat Genet. 2008; 40:862-870.

29. Reynolds SD, Zemke AC, Giangreco A, Brockway BL, Teisanu RM, Drake JA, Mariani T, Di PY, Taketo MM, Stripp BR. Conditional stabilization of beta-catenin expands the pool of lung stem cells. Stem Cells. 2008; 26:1337-1346.

30. Volckaert T, Dill E, Campbell A, Tiozzo C, Majka S, Bellusci S, De Langhe SP. Parabronchial smooth muscle constitutes an airway epithelial stem cell niche in the mouse lung after injury. J Clin Invest. 2011; 121:4409-4419.

31. Brody AR, Hook GE, Cameron GS, Jetten AM, Butterick CJ, Nettesheim P. The differentiation capacity of Clara cells isolated from the lungs of rabbits. Lab Invest. 1987; 57:219-229.

32. He XC, Yin T, Grindley JC, Tian Q, Sato T, Tao WA, Dirisina R, Porter-Westpfahl KS, Hembree M, Johnson T, Wiedemann LM, Barrett TA, Hood L, Wu H, Li L. PTENdeficient intestinal stem cells initiate intestinal polyposis. Nat Genet. 2007; 39:189-198.

33. Oliver JR, Kushwah R, Wu J, Cutz E, Yeger H, Waddell TK, Hu J. Gender differences in pulmonary regenerative response to naphthalene-induced bronchiolar epithelial cell injury. Cell Prolif. 2009; 42:672-687.

34. Linnoila RI, Jensen-Taubman S, Kazanjian A, Grimes HL. Loss of GFI1 impairs pulmonary neuroendorine cell proliferation, but the neuroendocrine phenotype has limited impact on post-naphthalene airway repair. Lab Invest. 2007; 87:336-344.

35. Kim H, Zamel R, Bai XH, Liu M. PKC activation induces inflammatory response and cell death in human bronchial epithelial cells. PLoS One. 2013; 8:e64182. 